\title{
Por uma história institucional da sociologia da saúde
}

\section{For an institutional history of the sociology of health}

\author{
Everardo Duarte Nunes \\ Professor, Faculdade de Ciências Médicas/Universidade Estadual de Campinas. \\ Campinas - SP - São Paulo \\ evernunes@uol.com.br
}

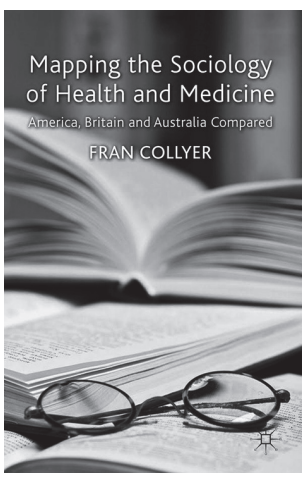

COLLYER, Fran. Mapping the sociology of health and medicine: America, Britain and Australia compared. Basingstoke: Palgrave Macmillan. 2012. 325p.
$\mathrm{O}_{\mathrm{i}}^{\mathrm{p}}$ percurso histórico da sociologia médica/saúde e de sua institucionalização tem sido investigado há algum tempo, e a ideia de desenvolvê-lo tomando como referência o conceito de institucionalização foi usada por Samuel W. Bloom (1921-2006) em dois momentos. Primeiro quando recebeu o Leo G. Reeder Award, em 1989, e apresentou seu discurso à American Sociological Association, relatando seu ingresso no campo da sociologia médica na década de 1950 e verificando que cerca de quatro décadas depois a sociologia médica estava bem estabelecida, mas "não como uma ciência social da medicina como tantos de nossos amigos médicos, como Virchow, desejavam. Nosso papel de acadêmicos críticos tem sido o de realçar a separação" (Bloom, 1990, p.7). Num segundo momento, Bloom (2002) apresentou uma pormenorizada narrativa que abrangeu a história da sociologia médica americana, seus antecedentes, precursores, pioneiros e contemporâneos, e as instituições - departamentos universitários, hospitais, fundações, organismos nacionais e internacionais, associações - onde decorreu a trajetória dessa disciplina, incluindo análises das principais produções e publicações.

Embora existam outros trabalhos que analisam a sociologia médica nos EUA e em outros países - por exemplo, Cockerham (1983) -, faltava uma pesquisa que abordasse a "cartografia social" do campo, comparando diferentes desenvolvimentos nacionais e usando a linguagem de Levine (2015), sobre a sociologia - das "tradições" que marcaram essas "visões" da sociologia médica/da saúde. É nessa perspectiva que se enquadra a pesquisa de Fran Collyer (2012) Mapping the sociology of health and medicine: America, Britain and Australia compared, na qual é empregada, de forma ampliada, a noção de processo de institucionalização.

Professora-associada da Universidade de Sydney (Austrália), Collyer destaca-se como uma das mais importantes sociólogas no campo da medicina e da saúde. Atualmente são 
três seus principais campos de pesquisa: a história institucional da disciplina, a produção e troca de conhecimento num contexto global e a crescente privatização dos serviços australianos de saúde.

Para ela, seu trabalho "é uma contribuição da sociologia do conhecimento para os debates correntes sobre a história da sociologia, sobre a maneira como disciplinas acadêmicas são formadas e o quão resilientes elas podem ser em face de mudanças rápidas (e radicais) no ambiente universitário" (p.1). Objetiva desvendar a institucionalização da "sociologia da saúde e da medicina" em diferentes cenários. Esclarece optar por essa denominação "parcialmente como um compromisso entre a 'sociologia da saúde', comumente usada no cenário australiano, e a 'sociologia médica' dos britânicos e americanos" (p.2). Segundo Collyer, "há um perigo em assumir que a história de uma disciplina pode ser adequadamente documentada traçando seus precursores intelectuais e um conjunto de ideias ou teorias-chave" (p.4). O caminho apontado passa por "examinar a história institucional" (p.7). Segundo Collyer (p.7, 8), as histórias institucionais constroem-se quando "ideias e práticas" são "nutridas, desenvolvidas e transmitidas" em "redes sociais, sociedades, centros de pesquisas universitários, escolas, departamentos etc.". Explica que, embora as trajetórias cognitivas e institucionais de uma disciplina estejam "entrelaçadas ... separadas completamente somente no nível analítico", no foco institucional analisa-se um processo no qual se incorporam as práticas sociais. Outro ponto fundamental nessa pesquisa é quando a autora estabelece que nem as teorias intelectuais internalistas e nem as externalistas "são em si mesmas suficientemente robustas para explicar a formação das disciplinas e suas mudanças históricas" (p.13, 14). Assim, adota a perspectiva segundo a qual "as disciplinas são reconfiguradas como locais de ação social e como instituições que estruturam, regulam e controlam essa ação". Todas as questões teóricas são expostas em um longo capítulo que aprofunda questões sobre as disciplinas e processos tomados como referências para se conhecer o campo institucional.

Fundamental para a abordagem empírica foi a retomada do conceito de processo de institucionalização e a reformulação de um modelo para investigar a construção de uma disciplina. A autora critica alguns trabalhos (Ben-David, Oberschall, Bloom) que utilizaram o conceito dizendo que "nenhum desses estudos pode ser caracterizado como um processo de explorações completamente teorizado ou sistematizado de institucionalização". Mesmo o trabalho de Bloom, citado inicialmente, "oferece um raro exemplo da discussão do conceito de institucionalização, embora seja breve e largamente ignorado nas páginas restantes de seu livro" (p.51).

Para Collyer, as fases da institucionalização apresentam os seguintes desenvolvimentos: $1^{a}$ fase: O foco é a "conectividade e comunicação", quando grupos ou encontros são extremamente informais e amigos e colegas trocam suas experiências sobre disciplinas e problemas, não enfatizando a discussão teórica per se, e não hierarquizando e/ou estabelecendo papéis fixos e obrigatórios; $2^{a}$ fase: ocorre uma "regularização" dos discursos, práticas e formas de organização; maior frequência de encontros e eventos e formação de alguns grupos de pesquisa ou de ensino, pequenos financiamentos, participação de membros de outras disciplinas e atração de novos participantes; $3^{\mathrm{a}}$ fase: caracteriza-se por um processo de "incorporação", incluindo obter um local na universidade e criar a própria identidade; 
obter recursos materiais e representação no corpo universitário; esforços são feitos para alcançar visibilidade nos noticiários, artigos, conferências etc.; $4^{\text {a }}$ fase: "legitimação" - completa-se o processo; legaliza-se alguma informalidade ainda existente e criam-se periódicos especializados, associações profissionais e departamentos e o credenciamento da disciplina passa pelas lideranças profissionais e membros sêniores (p.52-54).

Ancorada nessas formulações, Collyer irá narrar o processo de institucionalização de três sociologias "não somente como as arenas de conhecimento formal, mas também locais de ação social, estruturas institucionais, profissões, e elas mesmas estruturadas pela classe e capitalismo" (p.75). A autora recupera a história institucional nos EUA, Reino Unido e Austrália, incluindo as semelhanças e as diferenças e destaca as "novas formas de conceitualizar as relações entre disciplinas e suas especialidades" e, ao mesmo tempo, entender a sociologia "tanto como uma disciplina e uma profissão" (p.14, 15).

Todas essas preocupações convergem para um elaborado estudo comparativo desses países, no qual é analisado o desenvolvimento da sociologia da saúde e medicina. Collyer pesquisou sete periódicos (Health Sociology Review, Journal of Health and Social Behavior, Sociology of Health and Illness, Social Science and Medicine, Journal of Sociology, Australian and New Zealand Journal of Public Health, Tasa Refereed Conference Proceedings), totalizando 811 artigos, selecionados randomicamente no período de 1990 a 2010, sendo 361 da Austrália, 225 do Reino Unido e 225 dos EUA. A análise de conteúdo foi utilizada combinando as abordagens qualitativa e quantitativa, levantando as seguintes variáveis (que não continham informações pessoais como idade, estado civil etc.): número de autores, gênero, afiliação universitária, contexto organizacional do primeiro autor (afiliação departamental no campo das disciplinas: sociologia, antropologia, epidemiologia etc.) ou campo multidisciplinar (ciências sociais, ciências da saúde, humanidades, ciências da vida etc.). Outros dados levantados referem-se ao uso das teorias sociológicas, aos principais tópicos de saúde e medicina abordados no artigo e se a abordagem conferida à biomedicina é amigável ou crítica.

A utilização de dados quantitativos e qualitativos ao mapear territórios do conhecimento evidencia um original estudo de "cartografia social". Extensiva ao campo das ciências sociais e humanas, essa cartografia, "mais que mapeamento físico, trata de movimentos, relações, jogos de poder, enfrentamentos entre forças, lutas, jogos de verdade, enunciações, modos de objetivação, de subjetivação, de estetização de si mesmo, práticas de resistência e de liberdade" (Prado Filho, Teti, 2013, p.47). Os dados representam trajetórias, relações e tomadas de decisões, por exemplo, a participação em determinada instituição e departamento.

Nos três países maioria significativa, acima de 90\%, trabalha na universidade ou em institutos de ensino superior, com a presença de 53\% de sociólogos e outros profissionais em departamentos de sociologia e afins (antropologia, direito, história etc.). A participação em disciplinas e departamentos de medicina e de saúde pública e suas especialidades como epidemiologia, planejamento e outros cai para cerca de $10 \%$. A composição da disciplina da sociologia por gênero varia em cada país, havendo maior número de participantes mulheres na Austrália (69\%), percentual que é menor no Reino Unido (51\%) e nos EUA (50\%).

Para Collyer, o emprego da teoria e dos métodos sociológicos depende das filiações e identidades disciplinares dos autores. No geral, de todos os autores, 51\% fazem grande uso 
da teoria, valor que sobe para 57\% entre autores sociólogos. Na distribuição por países (grande uso) destaca-se o Reino Unido (59\%), ficando depois a Austrália (54\%) e, em terceiro lugar, os EUA (38\%).

A metodologia qualitativa é citada por $64 \%$ de todos os autores: Reino Unido (85\%), Austrália (70\%) e EUA (34\%); a quantitativa, 11\% nos três países: EUA (60\%), Austrália (15\%) e Reino Unido (7\%); a utilização de ambas metodologias (total de 11\%): Austrália (15\%), Reino Unido (9\%), EUA (6\%). Para Collyer, as diferenças entre os países, mesmo quando se consideram somente os autores sociólogos, e em especial as que se verificam nos EUA, poderiam ser explicadas pelo fato de que nesse país, comparativamente, a sociologia apresenta-se "menos homogênea", mais "polarizada", "moderadamente fraturada".

Quanto aos focos de interesse dos artigos, destacam-se nos três países os conhecimentos médicos ou de saúde; na Austrália e nos EUA sobressaem significados e linguagem; sistema de saúde e de bem estar na Austrália e no Reino Unido. Destacam-se, em especial, na Austrália, gênero e sexualidade, pesquisa em saúde e métodos; no Reino Unido, paciente e experiência com a enfermidade; desigualdade e doenças específicas, medicalização e indústria da saúde nos EUA.

As teorias em artigos de autores sociólogos foram agrupadas em teorias de consenso: 12\% (EUA), 2\% (Austrália), 3\% (Reino Unido); teorias interacionistas: 35\% (Reino Unido), 28\% (EUA), 13\% (Austrália); teorias de conflito: 39\% (Austrália), 31\% (EUA), 26\% (Reino Unido); teorias contemporâneas e "outras": 46\% (Austrália), 44\% (Reino Unido), 30\% (EUA).

Os autores citados com mais frequência, do total de 118, são: Strauss, Foucault, Lupton, Turner, Giddens, Goffman, Bury, Freidson, Gareth Williams, Conrad, Simon Williams, Parsons, Kleiman, Mechanic, Bourdieu, Armstrong, Charmaz, Corbin, McKinlay, Willis. Collyer chama a atenção para alguns fatos relacionados aos autores; primeiro, o forte impacto de dois teóricos europeus (Foucault e Bourdieu) nos três países; segundo, a atenção maior dada aos autores do próprio país, variando a adesão a autores de fora; não que esses sejam completamente ignorados, mas é muito forte a presença dos autores "locais" entre os americanos e britânicos e mais aberta entre os australianos.

De um modo geral, os resultados apontam que "a configuração da disciplina difere em alguma extensão em cada local"; por exemplo, nos EUA, "a sociologia médica é vista por muitos como uma disciplina com direitos próprios", e na Austrália, "como um campo especializado da disciplina [sociologia]" (p.270). Mas, como analisa Collyer, apesar das diferenças, "seria exagerado" concluir que há três diferentes sociologias. Nesse sentido, para a autora, o campo traz as marcas da sociologia pós-1950: é mais diversificado, multiparadigmático e compartilha uma rede ampliada de relações de autores e grupos (p.275).

O interessante no trabalho de Collyer é que ela combina diversas abordagens: histórica, sociológica, qualitativa, quantitativa. Assim sendo, é uma narrativa pluralista na linguagem de Levine (2015). Nem todos concordam com essa perspectiva. Short (2013, p.333), ao analisar as vertentes teóricas do trabalho de Collyer, anota que se sentiu "frustrada" com o relato que "acomoda múltiplas abordagens conceituais em sociologia"; inicialmente "uma sociologia do sistema social e outra da ação social", depois, as abordagens "positivistas e humanistas, complementadas com uma leitura althusseriana de Marx que se baseia em uma 
epistemologia realista e materialista", e, finalmente, a "tradição interpretativa sociológica que se estende de Weber em diante". Para Short, "essas abordagens conceituais poderiam ter sido localizadas em momentos e lugares específicos de forma mais adequada".

Penso que o percurso narrativo de Collyer possibilitou diálogos com a realidade estudada, trazendo mais pontos positivos do que negativos e que a pesquisa, de modo geral, se situa como um bom exemplo no campo da sociologia do conhecimento, sendo bem fundamentada teórica e metodologicamente.

\section{AGRADECIMENTOS}

O autor contou com bolsa produtividade do CNPq (Proc. 303983/2014-0).

\section{REFERÊNCIAS}

BLOOM, Samuel W.

Word as scalpel: a history of medical sociology.

New York: Oxford University Press. 2002.

BLOOM, Samuel W.

Episodes in the institutionalization of medical sociology: a personal view. Journal of Health and Social Behavior, v.31, n.1, p.1-10. 1990.

COCKERHAM, William C.

The state of medical sociology in the United States, Great Britain, West Germany and Austria: applied vs. pure theory. Social Sciences and Medicine, v.17, n.20, p.1513-1527. 1983.

COLLYER, Fran.

Mapping the sociology of health and medicine: America, Britain and Australia compared. Basingstoke: Palgrave Macmillan. 2012.
LEVINE, Donald N.

The variable status of the classics in differing narratives of the sociological tradition. Journal of Classical Sociology, v.15, n.4, p.305-320. 2015.

PRADO FILHO, Kleber; TETI, Marcela Montalvão.

A cartografia como método para as ciências humanas e sociais. Barbaroi, n.38, p.45-49. Disponível em: http://pepsic.bvsalud.org/ scielo.php?script $=$ sci_arttext\&pid $=$ S0104$65782013000100004 \& \operatorname{lng}=\mathrm{pt} \& \mathrm{nrm}=$ iso. Acesso em: 18 abr. 2017. 2013.

SHORT, Stephanie.

Mapping the sociology of health and medicine: America, Britain and Australia compared. Health Sociology Review, v.22, n.3, p.332-333. (Review). 2013. 